\title{
Reconfigurable Voltage Mode Phase Shifter using Low Voltage Digitally Controlled CMOS CCII
}

\author{
Iqbal A. Khan", Ahmed M. Nahhas \\ Department of Electrical Engin eering, Faculty of Engineering and Islamic Architecture, Umm Al Qura University, Makkah, Saudi Arabia
}

\begin{abstract}
The low voltage digitally controlled current conveyors have been used to realize the digitally controlled reconfigurable continuous time first order voltage mode phase shifters. Each of the realized phase shifters uses two digitally controlled current conveyers along with three passive elements. The realized phase shifters provide dig ital control to phase angle through an $\mathrm{n}$-bit digital control word. The realized digitally controlled continuous time phase shifters are designed and verified using PSPICE and the results thus obtained justify the theory.
\end{abstract}

Keywords Current Conveyors, Phase Shifter, Filter

\section{Introduction}

Introduction of digital control to the current conveyor (CCII) has boosted its functional flexibility and versatility in addition to its higher signal bandwidth, greater linearity and large signal bandwidth[1-10]. This digital control has eased the on chip control of continuous time systems through digital word with high resolution capability and reconfigurability[1-5],[10].

This paper basically deals with the realization of reconfigurable continuous time first order voltage mode phase shifters using Low voltage dig itally controlled CCII. Each of the realized phase shifters uses two digitally controlled current conveyors along with three passive elements. The realized phase shifters provide dig ital control to phase angle through an n-bit digital control word. To verify the theory, the realized digitally controlled continuous time phase shifters are designed and verified using PSPICE and the results thus obtained justify the theory.

\section{The Circuit}

The digitally controlled CCII sy mbol is shown in "Figure 1(a)" and its CMOS implementation with 4-bit control is shown in "Figure 1(b)". The current summing network (CSN) is included at port-X[1-4],[9],[10]. The transfer matrix can be expressed as follows.

* Corresponding author:

iqbalakhan19@rediffmail.com(Iqbal A. Khan)

Published online at http://journal.sapub.org/eee

Copyright (C) 2012, Scientific \& Academic Publishing. All Rights Reserved

$$
\left[\begin{array}{l}
I_{Y} \\
V_{X} \\
I_{Z-}
\end{array}\right]=\left[\begin{array}{ccc}
0 & 0 & 0 \\
1 & 0 & 0 \\
0 & -N & 0
\end{array}\right]\left[\begin{array}{c}
V_{Y} \\
I_{X} \\
V_{Z}
\end{array}\right]
$$

Thus the port voltages and currents for the digitally programmab le current conveyor (DPCCII) can be expressed as $\mathrm{I}_{\mathrm{Y}}=0, \mathrm{~V}_{\mathrm{X}}=\mathrm{V}_{\mathrm{Y}}$ and

$$
I_{Z_{-}}=-N I_{X}
$$

where, $\mathrm{N}$ is an $\mathrm{n}$-bit dig ital control word.

The voltage mode phase shifters using low voltage digitally controlled CMOS DPCCII are shown in "Figure 2". The DPCCII- uses the CSN at port-Z- as shown in "Figure 1(b)". The routine analysis yields the voltage transfers function for the reconfigurable phase shifter-I of "Figure 2(a)" as

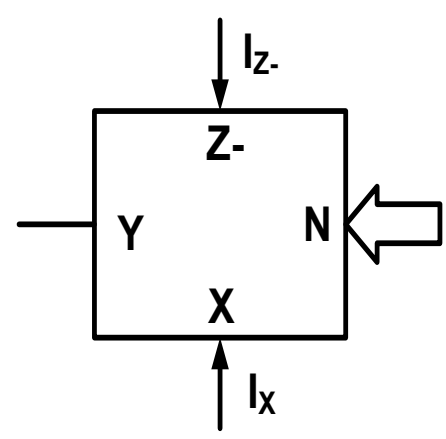

Figure 1(a). Symbol for 4-bit DPCCII- 


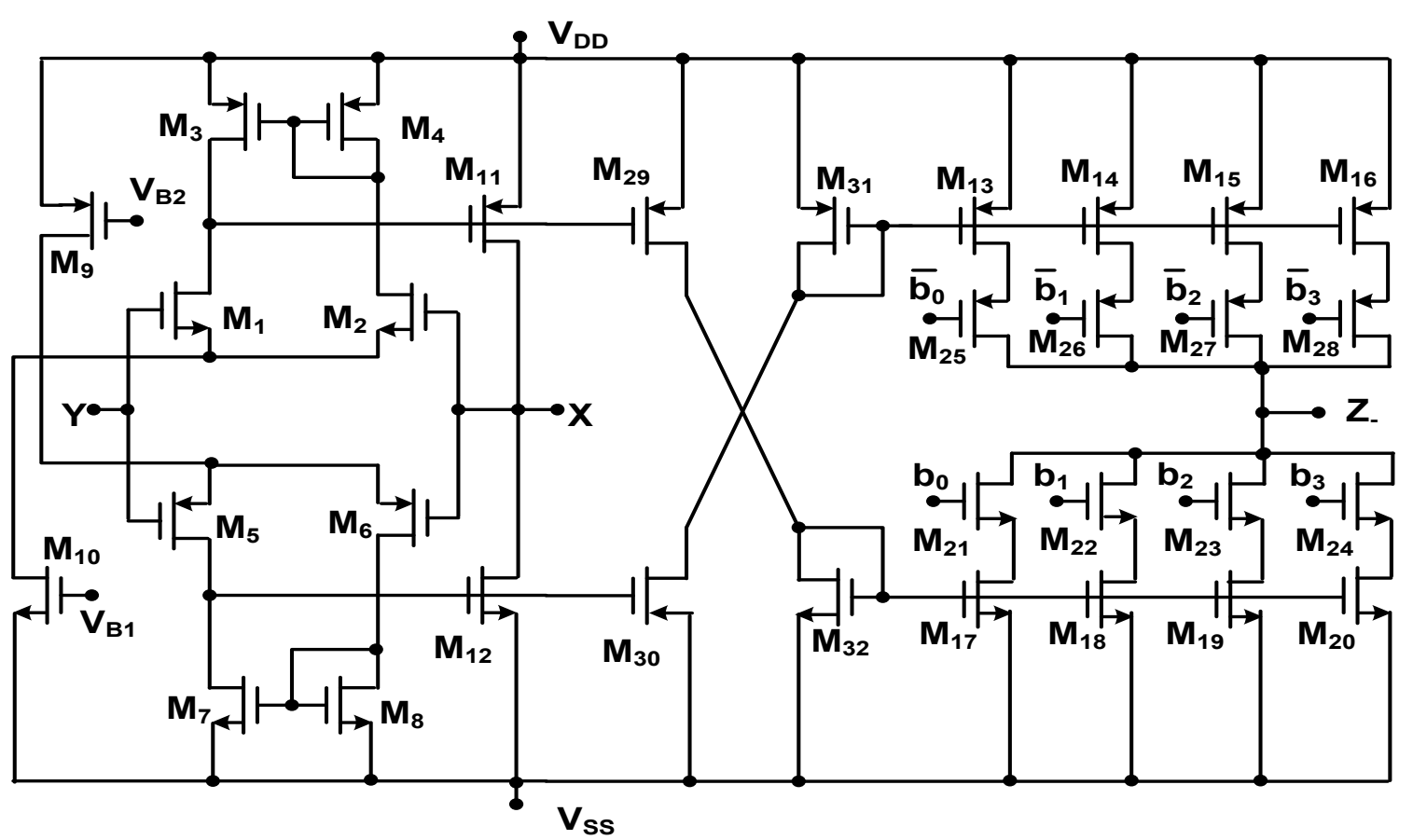

Figure 1(b). The CMOS implementation of a 4-bit DPCCII- with CSN at port Z-

The voltage mode phase shifters using low voltage digitally controlled CMOS DPCCII are shown in "Figure 2". The DPCCII- uses the CSN at port-Z- as shown in "Figure 1(b)". The routine analysis yields the voltage transfers function for the reconfigurable phase shifter-I of "Figure 2(a)" as

$$
\frac{V_{\text {OUT }}}{V_{I N}}=\frac{S-\frac{N}{C R_{1}}}{S+\frac{N}{C R_{2}}}
$$

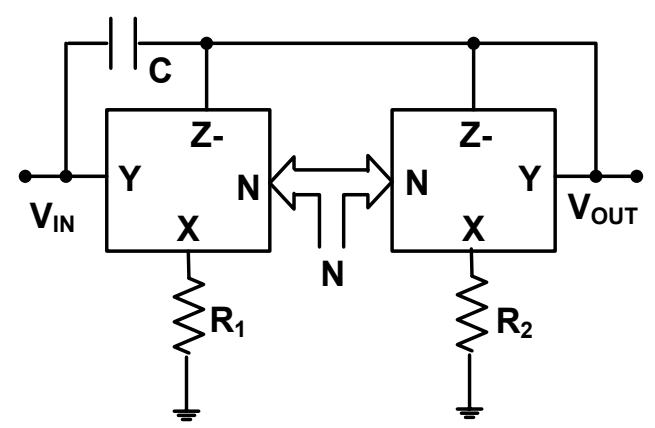

Figure 2(a). The reconfigurable phase shifter-I

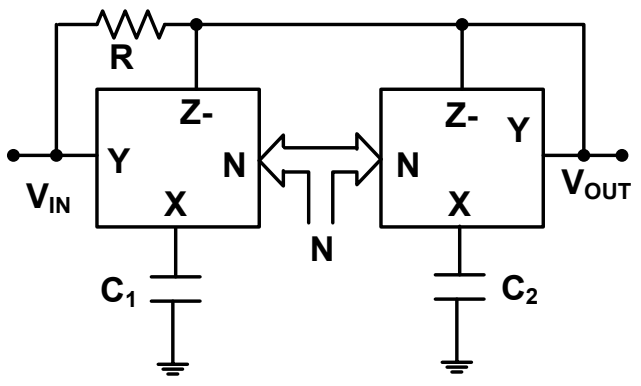

Figure 2(b). The reconfigurable phase shifter-II
With $\mathrm{R}_{1}=\mathrm{R}_{2}=\mathrm{R}$, the phase shift angle

$$
\phi=\pi-2 \tan ^{-1}\left(\frac{\omega R C}{N}\right)
$$

Similarly, the voltage transfers function for the reconfigurable phase shifter-II of "Figure 2(b)" can be expressed as

$$
\frac{V_{\text {OUT }}}{V_{I N}}=-\frac{C_{1}}{C_{2}} \times \frac{S-\frac{1}{N R C_{1}}}{S+\frac{1}{N R C_{2}}}
$$

With $\mathrm{C}_{1}=\mathrm{C}_{2}=\mathrm{C}$, the phase shift angle

$$
\phi=-2 \tan ^{-1}(\omega R C N)
$$

It is thus evident fro mequations (4) and (6) that the phase angle between output and input of the two phase shifters can be controlled with the digital control word $\mathrm{N}$.

\section{The Effect of Non-Idealities}

Taking the non-idealities of CCIIs into account, the relationship of the terminal voltages and currents can be rewritten as:

$$
V_{X}=\beta_{k} V_{Y}, I_{Z-}=-\alpha_{k} I_{X}
$$

Where, in equation (7) $\beta_{\mathrm{k}}$ is the voltage transfer gain from terminal-Y to terminal-X for the kth CCII and $\alpha_{k}$ is the current transfer gains for kth CCII from X to Z- respectively. Using equation (7) the ideal transfer functions and the phase angles given in (3), (4) and (5), (6) respectively for the circu it of" Figure 1(a)" and "Figure 1(b)", yields the non-ideal transfer functions and the phase shifts as follows. 


$$
\frac{V_{\text {OUT }}}{V_{I N}}=\left[\frac{S-\frac{\alpha_{1} \beta_{1} N}{R C}}{S+\frac{\alpha_{2} \beta_{2} N}{R C}}\right]
$$

With $\alpha 1=\alpha 2=\alpha$ and $\beta 1=\beta 2=\beta$

$$
\begin{gathered}
\phi=\pi-2 \tan ^{-1}\left(\frac{\omega R C}{\alpha \beta N}\right) \\
\frac{V_{\text {OUT }}}{V_{I N}}=\frac{\alpha_{1} \beta_{1}}{\alpha_{2} \beta_{2}}\left[\frac{S-\frac{1}{\alpha_{1} \beta_{1} R C N}}{S+\frac{1}{\alpha_{2} \beta_{2} R C N}}\right]
\end{gathered}
$$

Again with $\alpha_{1}=\alpha_{2}=\alpha$ and $\beta_{1}=\beta_{2}=\beta$

$$
\phi=-2 \tan ^{-1}(\alpha \beta \omega R C N)
$$

From equations (8) through (11) it is evident that the phase angles are affected slightly due to the non idealities.

\section{Design and Verification}

The realized digitally controlled current mode first order phase shifter of "Figure 2(a)", was designed and verified by performing PSPICE simu lation with supply voltage $\pm 0.75 \mathrm{~V}$ using CMOS TSMC $0.25 \mu \mathrm{m}$ technology parameters. The CMOS DPCCII with 4-bit current summing network at port-Z- of "Figure 1(b)" was used. The aspect ratios used are given in the Table 1 . In itially the phase shifter was designed for a phase angle $\phi=29^{\circ}$ at a constant frequency $f_{0}=100$ $\mathrm{KHz}$ with $\mathrm{N}=1$. Assuming $\mathrm{C}=1 \mathrm{nF}$, equation (4) y ields $\mathrm{R}=$ $6.36 \mathrm{~K} \Omega$. Then the phase angle $\phi$ was controlled through digital control word $\mathrm{N}$. The variation of observed and the theoretical phase angles with different control words ' $\mathrm{N}$ ' at $f_{0}$ $=100 \mathrm{KHz}$ are given in "Figure 3 ". The transfer gain and the input, output wave shapes at $\mathrm{N}=4$ are shown in "Figure 4". The variation of phase angle with frequency at different digital control word ' $\mathrm{N}$ ' is shown in "Figure 5". Thus the results of "Figure 3" through "Figure 5" clearly confirm the close conformity with the theory.

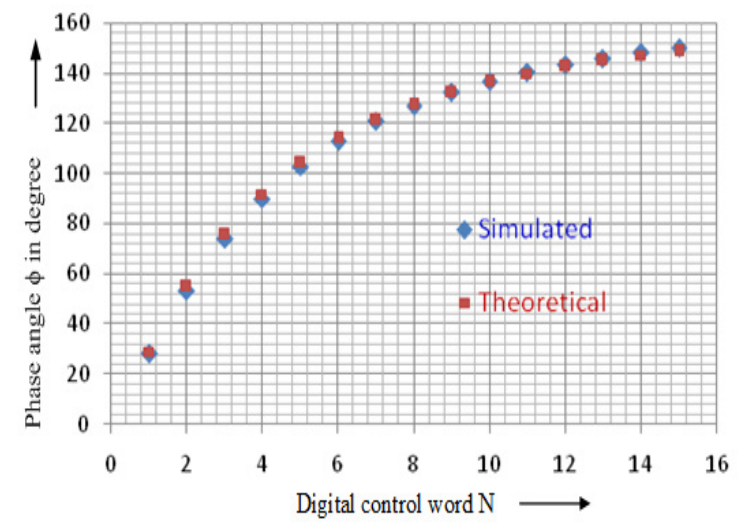

Figure 3. Phase angle variation with digital control word $\mathrm{N}$ at a const ant frequency $f_{0}=100 \mathrm{KHz}$

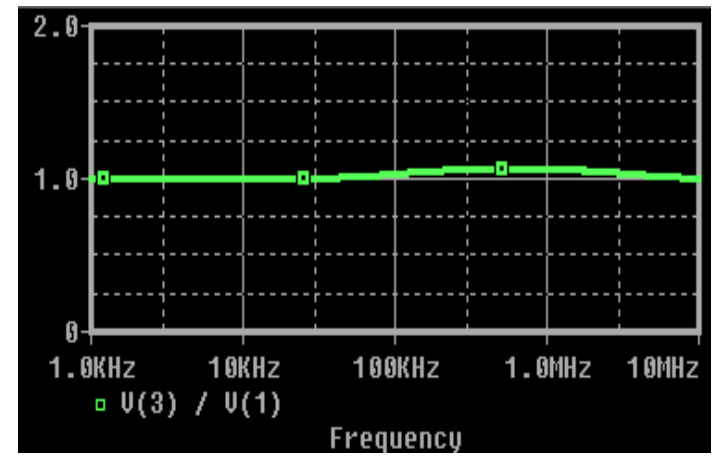

Figure 4(a). Gain Vs frequency response of the DCPS1 at $\mathrm{N}=4$

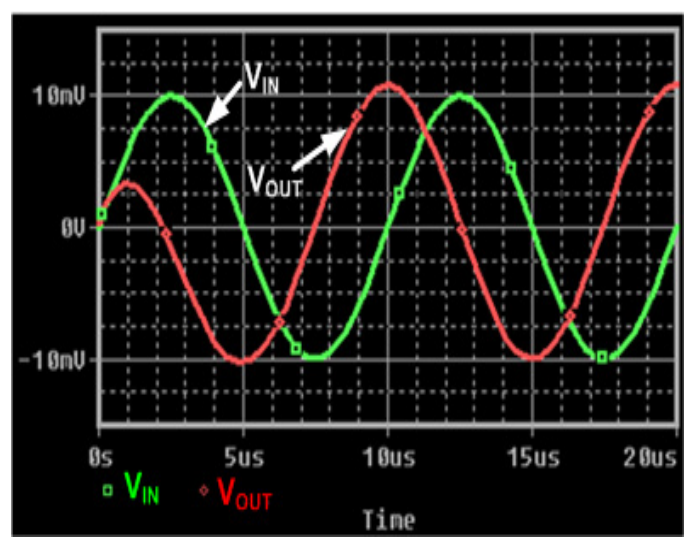

Figure 4(b). The input VIN and output VOUT wave shapes at $\mathrm{f}=100 \mathrm{KHz}$ and $\mathrm{N}=4$

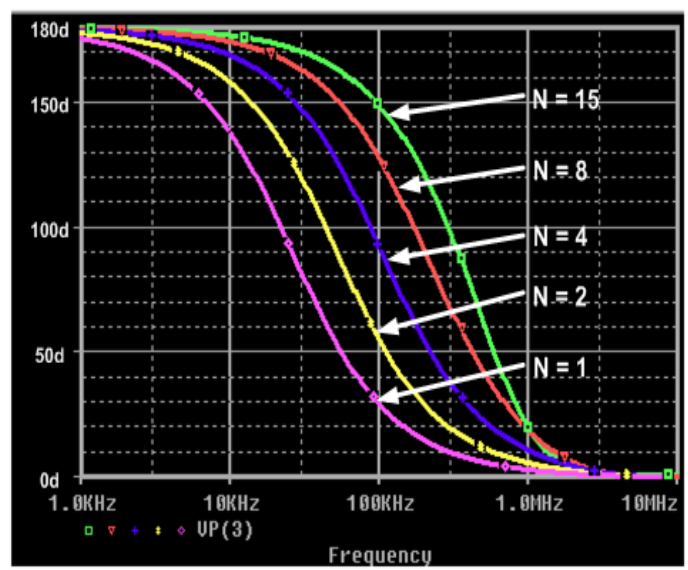

Figure 5. The phase vs frequency response at different digital control word $\mathrm{N}$

Table 1. The aspect ratios of the MOSFETs of the DPCCII

\begin{tabular}{|c|c|c|}
\hline MOSFET s & W $\mu \mathrm{m}$ & $\mathrm{L} \mu \mathrm{m}$ \\
\hline $\mathrm{M}_{1}, \mathrm{M}_{2}, \mathrm{M}_{5}, \mathrm{M}_{6}$ & 5 & 0.25 \\
\hline $\mathrm{M}_{3}, \mathrm{M}_{4}, \mathrm{M}_{7}, \mathrm{M}_{8}$ & 0.5 & 0.5 \\
\hline $\mathrm{M}_{9}, \mathrm{M}_{10}$ & 0.5 & 0.25 \\
\hline $\begin{array}{l}\mathrm{M}_{11}, \mathrm{M}_{12}, \mathrm{M}_{13}, \mathrm{M}_{14}, \\
\mathrm{M}_{15}, \mathrm{M}_{16}, \mathrm{M}_{17}, \mathrm{M}_{18}, \\
\mathrm{M}_{19}, \mathrm{M}_{23}, \mathrm{M}_{27}, \mathrm{M}_{31}\end{array}$ & 25 & 0.25 \\
\hline $\mathrm{M}_{20}, \mathrm{M}_{24}, \mathrm{M}_{28}, \mathrm{M}_{32}$ & 50 & 0.25 \\
\hline $\mathrm{M}_{21}, \mathrm{M}_{25}, \mathrm{M}_{29}, \mathrm{M}_{33}$ & 100 & 0.25 \\
\hline $\mathrm{M}_{22}, \mathrm{M}_{26}, \mathrm{M}_{30}, \mathrm{M}_{34}$ & 200 & 0.25 \\
\hline
\end{tabular}




\section{Conclusions}

Two new voltage mode digitally controlled first order phase shifters have been realized using low voltage dig itally controlled CMOS current conveyors. Each of the realized phas e shifters us es two dig itally controlled current conveyers along with three passive elements. The realized phase shifters provide digital control to phase angle through an n-bit control word. The realized digitally controlled continuous time phase shifters were designed and verified using PSPICE and the results thus obtained justify the theory.

\section{REFERENCES}

[1] T. M. Hassan and S. A. Mahmoud, "Low voltage digitally programmable band pass filter with independent control," IEEE International Conference on Signal Processing and Communications (ICSPC 2007), pp. 24-27, Dubai, UAE, 2007.

[2] I. A. Khan, M. R. Khan and N. Afzal, "Digitally programmable multifunctional filters using CCIIs," Journal of Active and Passive Electronic Devices, vol. 1, pp.213-220, 2006.

[3] I. A. Khan, M. R. Khan and N. Afzal, "A Digitally Programmable Impedance Multiplier using CCIIs with High Resolution Capability," Journal of Active and Passive Electronic Devices, vol. 8, pp. 247-257, 2009.
[4] T. M. Hassan and S. A. Mahmoud, "Fully programmable universal filter with independent gain, $\omega 0$ and $\mathrm{Q}$ control based on new digitally programmable CMOS CCII," Journal of Circuits, Systems and Computers, Vol. 18, No. 5, pp.875-897, 2009

[5] S. A. Mahmoud, M. A. Hashiesh, and A. M. Soliman, "Low-Voltage Digitally Controlled Fully Differential Current Conveyor," IEEE Transactions on circuits and Sy stems-I, vol. 52, No. 10, 2005.

[6] I. A. Khan, and S. Maheshwari, "Simple first order all-pass section using a single CCII," International Journal of Electronics, vol. 87, No. 3, pp. 303-306, 2000.

[7] R. Mita, G. Palumbo, and S. Pennisi, "1.5-V CMOS CCII+ with High Current-Drive Capability," IEEE Trans. CAS-II, vol. 50, No. 4, pp. 187-190, 2003.

[8] A. H. Madian, S. A Mahmoud and A. M. Soliman, "New 1.5V CMOS second generation current conveyor based on wide range transconductor," Analog Integrated Circuits and Signal Processing, vol. 49, pp. 267-279, 2006.

[9] I. A. Khan, P. Beg and M. T. Ahmed, "First Order Current Mode Filters and Multiphase Sinusoidal Oscillators Using MOCCIIs", Arabian Journal of Science and Engineering, Saudi Arabia, vol.32, No. 2C, pp. 119-126, Dec. 2007.

[10] I. A. Khan and M. T Simsim, "A Novel Impedance Multiplier using Low voltage Digitally Controlled CCII," Proc. IEEEE GCC Conference and Exhibition, Dubai, UAE, pp. 331-334, Feb. 19-22, 2011. 